\title{
Commentary \\ Normal adrenocortical function on initial testing in the intensive care unit: not a long-term warranty
}

Pierre-Edouard Bollaert

Service de Réanimation Médicale, CHU de Nancy, Nancy, France

Corresponding author: Pierre-Edouard Bollaert, pe.bollaert@chu-nancy.fr

Published: 2 July 2008

This article is online at http://ccforum.com/content/12/4/163

(c) 2008 BioMed Central Ltd

See related research by Wu et al., http://ccforum.com/content/12/3/R65

\begin{abstract}
There has been a lot of debate about the concept of relative adrenocortical insufficiency (often defined as a reduced response to corticotropin) as a pathophysiological explanation of steroid effects in septic shock. Less is known about the prevalence of absolute adrenocortical insufficiency based on more usual definitions (low baseline and corticotropin stimulated cortisol). A study by Wu and colleagues provides convincing evidence that critically ill patients could evolve from a normal adrenal status towards very low cortisol levels within a few days. Although the exact consequences of these findings deserve more investigation, adrenal testing should not be omitted in patients not improving their hemodynamic status.
\end{abstract}

In the previous issue of Critical Care, Wu and colleagues [1] report delayed adrenal insufficiency in 15 critically ill patients on the basis of a repeated plasma cortisol test among a prospective cohort of 53 patients who had normal or high cortisol levels on first testing and did not exhibit clinical improvement with treatment. Although 11 of these 15 patients received replacement doses of steroids, they had a longer length of stay in hospital and longer duration of mechanical ventilation. The authors must be congratulated for these findings, which add a new piece in the complex puzzle of adrenocortical function, steroid treatment and outcome in the intensive care unit (ICU).

The renewal of interest for adrenal testing in critically ill patients has been stimulated by the demonstration that patients with septic shock treated with moderate doses of hydrocortisone for seven to ten days displayed a more rapid shock reversal than untreated patients and a probable improved survival [2] and that septic patients not adequately increasing their plasma cortisol concentrations in response to a short corticotropin test had increased 28-day mortality $[3,4]$. Taken together, these findings led some physicians to
Critical Care 2008, 12:163 (doi:10.1186/cc6926)

suggest that these 'supraphysiological' doses of hydrocortisone were an opotherapy addressed to a new pathophysiological disorder: relative adrenal insufficiency (RAI). RAI remains a controversial issue for several reasons. Although most investigators would agree that its usual definition is an absolute cortisol increase $<9 \mu \mathrm{g} / \mathrm{dl}$ after a $250 \mu \mathrm{g}$ corticotropin IV bolus, irrespective of baseline cortisol value, others use criteria related to 'absolute' adrenocortical insufficiency where both baseline and stimulated cortisol values are considered. In addition, the diagnostic performance and reproducibility of the corticotropin test have been challenged [5]. The best way to validate the RAl concept would be to observe selective improvement in survival in patients with RAl who were treated with hydrocortisone replacement compared to untreated RAl patients. Although the study by Annane and colleagues [6] supported this view, the recent Corticus study [7] did not. The pathophysiological significance of RAI remains unknown $[8,9]$.

Conversely, 'absolute' adrenocortical insufficiency, usually defined as a low basal cortisol concentration that cannot be stimulated with corticotropin, seems to be uncommon in the ICU population, at least in patients tested on admission, except for those receiving etomidate to facilitate endotracheal intubation. In the paper by Wu and colleagues, of the patients who had initial cortisol levels that reasonably ruled out adrenocortical insufficiency, 25\% displayed low, and for 6 of them, very low, cortisol levels within a mean time of 8 days. Although, as the authors themselves acknowledged, neither corticotropin testing nor measurement of free cortisol were performed, these limitations would be more relevant to patients with borderline cortisol levels (about 10 to $15 \mu \mathrm{g} / \mathrm{dl}$ ) than to patients with lower values [9]. One should also keep in mind that albumin levels remained unchanged. In addition, these patients required dosages of norepinephrine to be

$\mathrm{ICU}=$ intensive care unit; $\mathrm{RAI}=$ relative adrenal insufficiency. 
doubled, suggesting clinical symptoms possibly related to absolute adrenocortical deficiency. Finally, the large decrease in cortisol values in the patients whose clinical status did not improve cannot be confounded with the usually observed slow decrease towards moderately high cortisol values observed for ICU patients [10].

Similar findings have been reported in septic patients who were further tested after a mean time of six days because of an inability to decrease vasopressor support and who displayed low cortisol values with a similar range to those in the study of $\mathrm{Wu}$ and colleagues. Resolution of vasopressor dependence was achieved with steroid replacement [11]. In a study on patients with liver disease, $16 \%$ of the patients initially tested as having normal adrenocortical function later developed absolute adrenocortical insufficiency according to conservative criteria [12]. Importantly, the patients had received no etomidate or ketoconazole in these two studies. Finally, the timing of onset of adrenocortical insufficiency suggests that what is often called 'shock rebound' just after stopping a seven- to ten-day course of moderate doses of steroids in septic shock patients could account for this delayed adrenocortical insufficiency, thus needing further testing $[7,13]$.

As for RAl, the mechanisms of this 'adrenal exhaustion' syndrome are unclear. It has been found previously that low levels of high-density lipoprotein are a good predictor of the subsequent development of adrenal failure [12,14]; highdensity lipoprotein could be a rate-limiting substrate of steroidogenesis in the adrenal cortex. However, this exciting hypothesis has to be confirmed in appropriately designed studies.

Could these results modify our current clinical practice? While awaiting further studies, we should agree with the keymessage of Wu and colleagues: normal initial adrenocortical function is not a warranty for the ICU stay and repeated testing is needed according to the clinical evolution of the patients. This message could also apply to patients recently treated with steroids for septic shock.

\section{Competing interests}

The author declares that they have no competing interests.

\section{References}

1. Wu J-Y, Hsu S-C, Ku S-C, Ho C-C, Yu C-J, Yang P-C: Adrenal insufficiency in prolonged critical illness. Crit Care 2008, 12: R65.

2. Annane D, Bellissant E, Bollaert PE, Briegel J, Keh D, Kupfer Y: Corticosteroids for severe sepsis and septic shock: a systematic review and meta-analysis. BMJ 2004, 329:480.

3. Annane D, Sébille V, Troché G, Raphaël JC, Gajdos P, Bellissant $\mathrm{E}$ : A 3-level prognostic classification in septic shock based on cortisol levels and cortisol response to corticotropin. JAMA 2000, 283:1038-1045.

4. de Jong MF, Beishuizen A, Spijkstra JJ, Groeneveld AB: Relative adrenal insufficiency as a predictor of disease severity, mortality, and beneficial effects of corticosteroid treatment in septic shock. Crit Care Med 2007, 35:1896-1903.
5. Loisa P, Uusaro A, Ruokonen E: A single adrenocorticotropic hormone stimulation test does not reveal adrenal insufficiency in septic shock. Anesth Analg 2005, 101:1792-1798.

6. Annane D, Sébille V, Charpentier C, Bollaert PE, François B, Korach JM, Capellier G, Cohen Y, Azoulay E, Troché G, ChaumetRiffaut $P$, Bellissant $E$ : Effect of treatment with low doses of hydrocortisone and fludrocortisone on mortality in patients with septic shock. JAMA 2002, 288:862-871.

7. Sprung CL, Annane D, Keh D, Moreno R, Singer M, Freivogel K, Weiss YG, Benbenishty J, Kalenka A, Forst H, Laterre PF, Reinhart K, Cuthbertson BH, Payen D, Briegel J; CORTICUS Study Group: Hydrocortisone therapy for patients with septic shock. N Engl J Med 2008, 358:111-124.

8. Dickstein G: On the term "relative adrenal insufficiency" - or what do we really measure with adrenal stimulation tests? J Clin Endocrinol Metab 2005, 90:4973-4974.

9. Arafah BM: Hypothalamic pituitary adrenal function during critical illness: limitations of current assessment methods. J Clin Endocrinol Metab 2006, 91:3725-3745.

10. Vermes I, Beishuizen A, Hampsink RM, Haanen C: Dissociation of plasma adrenocorticotropin and cortisol levels in critically ill patients: possible role of endothelin and atrial natriuretic hormone. J Clin Endocrinol Metab 1995, 80:1 238-1242.

11. Guzman JA, Guzman CB: Adrenal exhaustion in septic patients with vasopressor dependency. J Crit Care 2007, 22:319-323.

12. Marik PE: Adrenal-exhaustion syndrome in patients with liver disease. Intensive Care Med 2006, 32:275-280.

13. Oppert M, Schindler R, Husung C, Offermann K, Gräf KJ, Boenisch O, Barckow D, Frei U, Eckardt KU: Low-dose hydrocortisone improves shock reversal and reduces cytokine levels in early hyperdynamic septic shock. Crit Care Med 2005, 33:2457-2464

14. van der Voort PH, Gerritsen RT, Bakker AJ, Boerma EC, Kuiper MA, de Heide L: HDL-cholesterol level and cortisol response to synacthen in critically ill patients. Intensive Care Med 2003, 29:2199-2203. 